\title{
Cells susceptible to epithelial-mesenchymal transition are enriched in stem-like side population cells from prostate cancer
}

\author{
YONG LUO $^{1^{*}}$, XINHAO CUI $^{2^{*}}$, JIAHUI ZHAO ${ }^{1}$, YILI HAN $^{1}$, MINGCHUAN LI $^{1}$, \\ YUNHUA LIN $^{1}$, YONGGUANG JIANG ${ }^{1}$ and LING LAN ${ }^{3}$ \\ ${ }^{1}$ Department of Urology, Beijing Anzhen Hospital, Affiliated to Capital Medical University, Beijing 100029; \\ ${ }^{2}$ Department of Urology, Beijing Shijingshan Hospital, Beijing 100043; ${ }^{3}$ Department of Endocrinology, \\ Beijing Jishuitan Hospital, The 4th Clinical Medical College of Peking University, Beijing 100035, P.R. China
}

Received July 31, 2013; Accepted November 12, 2013

DOI: $10.3892 / o r .2013 .2905$

\begin{abstract}
Accumulating evidence suggests that epithelialmesenchymal transition (EMT) acts as an important factor for the promotion of tumor progression. Strategies for suppressing EMT remain the subject of ongoing research. In the present study, fluorescence-activated cell sorting (FACS) was used to isolate side population (SP) cells from human prostate cancer (PCa) cell lines and xenograft tissues. After identifying their molecular and functional stem-like characteristics, stem-like SP cells from a cell line and from xenograft tissue were transfected with hypoxia inducible factor-1 $\alpha$ (HIF-1 $\alpha)$. The potential of the prostate stem-like SP cells to undergo EMT was compared with that in their bulk counterparts after HIF-1 $\alpha$ introduction. Stem-like SP cells acquired more complete EMT molecular features and exhibited stronger aggressive capability than the homologous bulk population cells both in vitro (proliferation and invasion) and in vivo (tumorigenesis and metastasis formation). We, therefore, concluded that EMT is closely associated with tumor heterogeneity, and that $\mathrm{PCa}$ cells susceptible to EMT are enriched in stem-like SP cells. These findings disclose a new approach, targeting the cellular basis of the EMT process that may help to identify effective and accurate methods for suppressing tumor growth and preventing distant dissemination.
\end{abstract}

Correspondence to: Professor Yongguang Jiang, Department of Urology, Beijing Anzhen Hospital, Affiliated to Capital Medical University, Anzhenli Street, Chaoyang District, Beijing 100029, P.R. China

E-mail: jyganzhen@sohu.com

Professor Ling Lan, Department of Endocrinology, Beijing Jishuitan Hospital, The 4th Clinical Medical College of Peking University, 31 Xinjiekou East Street, Xicheng District, Beijing 100035, P.R. China E-mail: lanjingling0627@hotmail.com

\section{*Contributed equally}

Key words: side population cells, cancer stem cells, epithelialmesenchymal transition, prostate cancer, hypoxia inducible factor-1 $\alpha$, heterogeneity

\section{Introduction}

Prostate cancer (PCa) is a common malignancy associated with high morbidity and mortality. Radical prostatectomy combined with pharmacological androgen ablation is effective during the initial stages of the disease, yet the cancer often quickly progresses to form distant metastases for which no known effective therapy is available. The etiology of metastatic PCa remains poorly understood.

The process of epithelial-mesenchymal transition (EMT) is an important pathological process in tumor progression. When cancer cells interact with the surrounding mesenchymal environment, they lose epithelial cadherins, and aberrantly express certain mesenchymal proteins, causing them to transform into spindle-shape cells with stronger migrating capability (1). Previous studies have verified that EMT is one of the crucial processes through which cancer cells migrate from the primary microenvironment to distant sites $(2,3)$. It may also explain the process by which tumors evade host immune surveillance $(3,4)$ and acquire resistance to chemotherapy (5-7).

It is generally accepted that tumors are composed of a heterogeneous population of cells, among which only a small proportion, behaving as stem cells, have infinite self-renewal capacity, together with unlimited proliferation and differentiation potential. This subset of cells is highly efficient at propagating tumor progression, and they act functionally as cancer stem cells (CSCs) (8). CSCs have been shown to be involved in tumor progression, disease recurrence and therapeutic resistance (9).

EMT and CSCs act together to promote tumor progression. Several studies have established a crucial link between occurrence of tumor EMT and acquisition of stem cell-like properties $(10,11)$. However, the underlying correlation between these factors remains to be elucidated. In a previous study, we showed that hypoxia-inducible factor-1 $\alpha$ (HIF-1 $\alpha$ ) triggered EMT in human PCa cells (12). Here, we further compared the EMT activity of prostate CSCs with that of bulk population cells subjected to HIF-1 $\alpha$ transfection. Based on these findings, we attempted to define relationships between EMT and tumor heterogeneity, by identifying the possible 'cell carriers' involved in EMT, and thereby develop a potential cell target to suppress EMT progression. 


\section{Materials and methods}

Cell culture. Human PCa cell lines (LNCaP, PC-3, Du145, TSU-PrL and IA8) were maintained in Dulbecco's modified Eagle's medium (DMEM) containing $1 \mathrm{mM}$ sodium pyruvate, $2.5 \mathrm{mM}$ glutamine, $10 \%$ fetal bovine serum (FBS), $100 \mathrm{U} / \mathrm{ml}$ penicillin and $100 \mu \mathrm{g} / \mathrm{ml}$ streptomycin. Stem-like population cells were cultured in keratinocyte medium (ScienCell, Carlsbad, CA, USA) supplemented with $20 \mathrm{ng} / \mathrm{ml}$ epidermal growth factor (Sigma), $50 \mu \mathrm{g} / \mathrm{ml}$ bovine pituitary extract (Sigma), $2 \mathrm{ng} / \mathrm{ml}$ leukemia inhibitory factor (Sigma), $2 \mathrm{ng} / \mathrm{ml}$ stem cell factor (Sigma) and $100 \mathrm{ng} / \mathrm{ml}$ cholera toxin (Sigma). All cells were aseptically handled and grown at $37^{\circ} \mathrm{C}$ in a humidified incubator containing $5 \% \mathrm{CO}_{2}$. Cells transfected with HIF-1 $\alpha$ were grown in an atmosphere of $1 \%$ oxygen.

Fluorescence-activated cell sorting (FACS). Combinations of fluorochrome-conjugated monoclonal antibodies against human CD133 and CD44 (Miltenyi, Bergisch Gladbach, Germany) and the respective isotype controls were added to the cell suspension and incubated at $4^{\circ} \mathrm{C}$ in the dark for 15-30 min. After washing and fixing in PBS, the labeled cells were analyzed by flow cytometry. Gates were determined by analysis of double staining. Cells were also harvested for Hoechst 33342 staining, and verapamil (Sigma), an inhibitor of the ABCG2 transporter, was used to identify specific cell populations. A 350-nm UV laser was used to excite Hoechst 33342.

Analysis was performed using dual-wavelength analysis (blue, $424 \mathrm{~nm}$; red, $675 \mathrm{~nm}$ ). The side population was identified by gating the characteristic fluorescence emission profile. Equal numbers of side population (SP) and non-SP cells (NSP) were collected for the following experiments.

Colony formation assay. Colony formation assays were performed to evaluate the cell self-renewal potential in vitro. Briefly, 1,000 cells were suspended in DMEM containing $0.4 \%$ agarose, and overlaid onto a 6-cm dish (Corning Incorporated Corning, NY, USA). Cells were incubated for 1-3 weeks until colonies were visible. Only colonies with $>32$ cells were scored. Colony formation efficiency (CFE) was determined by the percentage of cells that initiated a clone.

HIF-1 $\alpha$ cDNA transfection. Recombinant plasmid pcDNA3.1(-)/HIF-1 $\alpha$ was transfected into stem-like SP cells and homologous non-SP cells using the Lipofectamine 2000 system (Life Technologies, Carlsbad, CA, USA). The cells were then cultured in medium containing $400 \mu \mathrm{g} / \mathrm{ml} \mathrm{G} 418$. After 4 weeks of selection, all non-transfected cells died and separate clones were visible in the transfected cells. These clones were further expanded using $200 \mu \mathrm{g} / \mathrm{ml} \mathrm{G} 418$.

Western blotting. Clarified protein lysates were electrophoretically resolved on denaturing SDS-PAGE and electro-transferred onto nitrocellulose membranes. The membranes were initially incubated with $5 \%$ non-fat dry milk in TBS for $2 \mathrm{~h}$, and then probed with the primary antibodies (all from Santa Cruz Biotechnology, Santa Cruz, CA, USA) against various proteins at $4^{\circ} \mathrm{C}$ overnight. The proteins tested were ABCG2, integrin $\alpha 2$, OCT4, CD44, Nanog, nestin (as stemness markers), HIF-1 $\alpha$ (as an EMT inducer), Glut-1 and
VEGF (as HIF-1 $\alpha$ target proteins), E-cadherin and CK18 (as epithelial markers), $\mathrm{N}$-cadherin, fibronectin, vimentin, cathepsin D, MMP-2 and uPAR (as mesenchymal markers) and GAPDH (as an internal control).

The membranes were hybridized with an appropriate horseradish peroxidase (HRP)-conjugated secondary antibody (Boshide Co., Ltd., Hebei, China) for $2 \mathrm{~h}$ at room temperature. An enhanced chemiluminescence system (Amresco, Solon, $\mathrm{OH}$, USA) was used to detect the immunopositive protein bands.

In vitro invasion assay. Polycarbonate filters $(8-\mu \mathrm{m})$ (Millipore, Billerica, MA, USA) were coated with $50 \mu \mathrm{g} /$ $\mathrm{cm}^{2}$ of reconstituted Matrigel (Sigma). Fifty thousand cells in $300 \mu \mathrm{l}$ of serum-free growth medium were seeded into the upper chamber. Cells were incubated in normoxic conditions and allowed to migrate toward the complete growth medium for 24,48 and $72 \mathrm{~h}$. Non-invading cells were removed mechanically using cotton swabs, and the migrated cells located on the lower surface were fixed with methanol.

The number of migrating cells was determined by counting 10 high-power fields of view on each membrane. Data are presented as the mean number of cells per field. Each experiment was repeated three times.

MTT assay. Cells (1,000/well) were placed into 96-well plates. At various time-points, MTT solution was added and incubated for an additional $4 \mathrm{~h}$. Cell-associated MTT crystals were dissolved in DMSO. The color intensity was measured at $570 \mathrm{~nm}$ using a Bio-Rad Technologies microplate reader.

Xenograft experiments. Surgery was performed under sodium pentobarbital anesthesia, and all efforts were made to ameliorate suffering. Six-week-old male nude mice (Charles River Laboratories International) were injected subcutaneously with $5 \times 10^{5}$ cells in the left lateral flank. Animals (15 per group) were monitored daily, and tumor volumes were determined by the formula: $\mathrm{V}=\left(\mathrm{LW}^{2}\right) / 2$, where $\mathrm{L}$ is the length and $\mathrm{W}$ is the width. Eight weeks later, tumors and other organs were fixed overnight at $4{ }^{\circ} \mathrm{C}$ in $4 \%$ paraformaldehyde and embedded in paraffin for histological analysis. Tumor tissue cells were used for primary culture in the subsequent experiments.

This part of the study was carried out in strict accordance with the recommendations in the Guide for the Care and Use of Laboratory Animals in the Weatherall Report. In addition, the protocol was approved by the Committee on the Ethics for Animal Experiments of the Capital Medical University.

Immunohistochemical staining. Paraformaldehyde-fixed cells and paraffin-embedded sections of xenograft cancer tissues were used for either H\&E or immunostaining. Primary antibodies against stem cell markers (ABCG2, OCT4, integrin $\alpha 2$, Nanog, CD44 or nestin) and EMT markers (E-cadherin, vimentin, MMP-2, $\alpha$-SMA and cathepsin D) were used. Immunohistochemical analysis was carried out using a commercially available kit (Boshide). Positive and negative controls were used throughout all immunostaining protocols.

Statistical analysis. Statistical analysis was carried out using the Statistical Package for Social Sciences (SPSS), version 
A
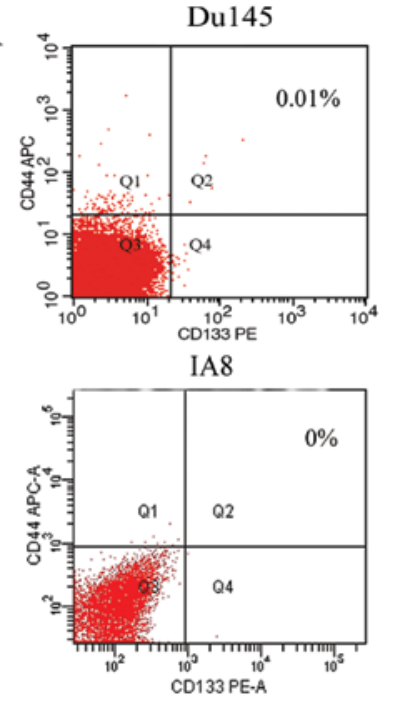

LNCaP

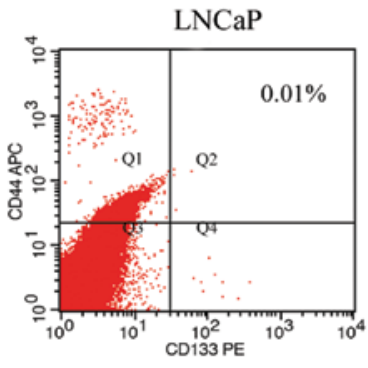

TSU-PrL

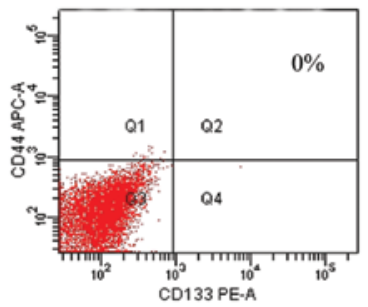

PC-3

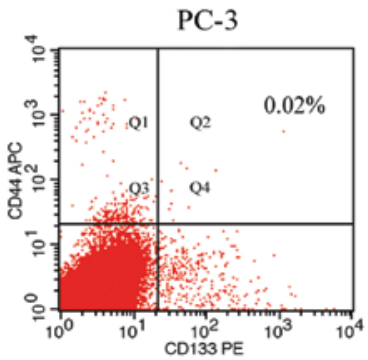

B
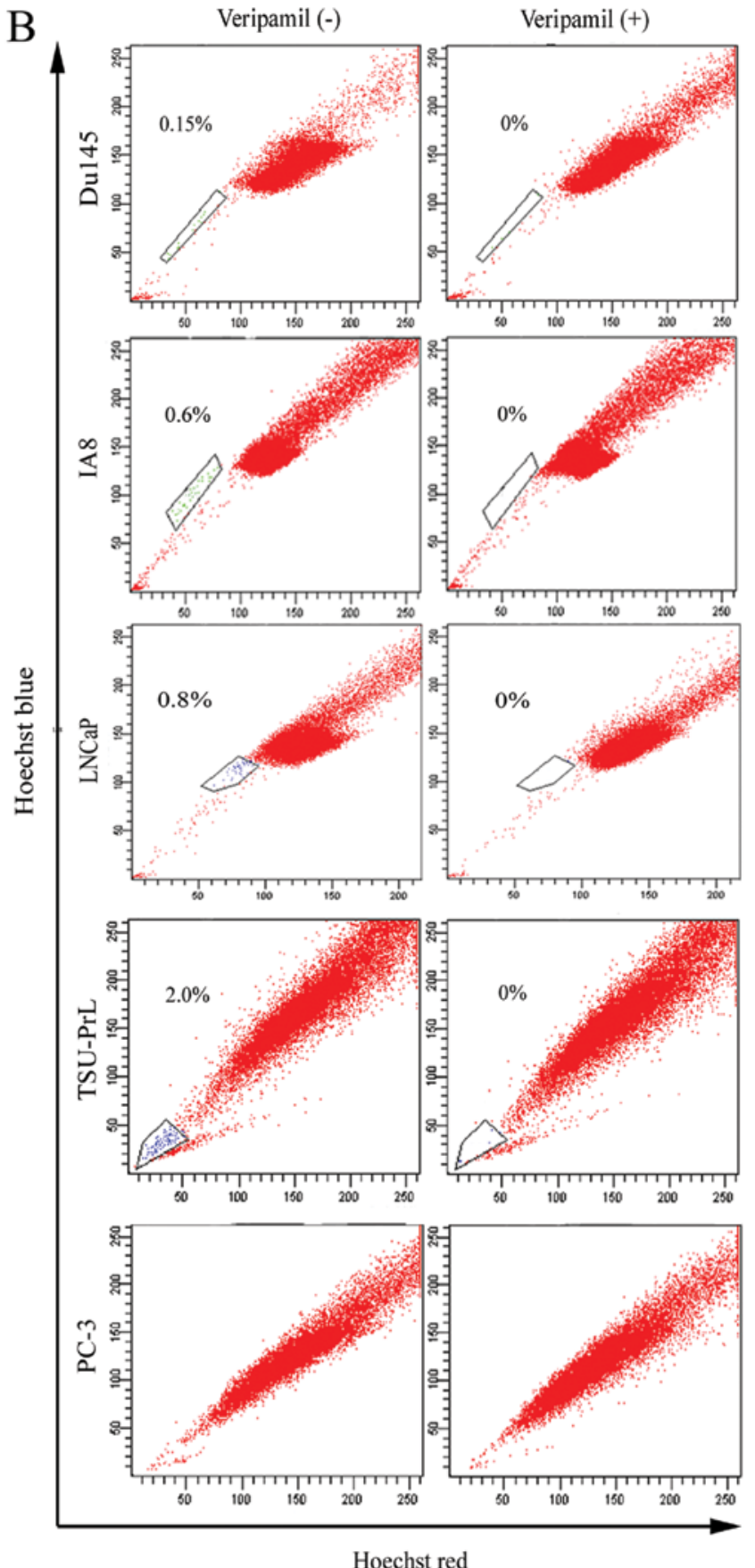

Figure 1. Identification of stem-like cells in prostate cancer cell lines. (A) No detectable population of CD133 ${ }^{+} \mathrm{CD} 44^{+}$cells was found in the IA8 and TSU-PrL cell lines, and only extremely small populations were detected in the Du145, LNCaP and PC-3 cell lines (0.01, 0.01 and $0.02 \%$, respectively). (B) A specific side population (SP) was outlined and detected in the Du145, IA8, LNCaP and TSU-PrL cell lines. The percentage of SP cells was $\sim 0.15 \%$ in Du145, $0.6 \%$ in IA $8,0.8 \%$ in LNCaP and $2.0 \%$ in TSU-PrL cells. No specific SP cells were obtained from the PC-3 cell line.

13.0, for Windows. Data are presented as means \pm standard deviations (SD). Student's t-tests were used to compare results between the different experimental groups. A value of $\mathrm{P}<0.05$ was considered to indicate a statistically significant result.

\section{Results}

Evidence for stem-like cells in the LNCaP cell line. According to a previous finding (13), cells with the phenotype of $\mathrm{CD} 133^{+} \alpha_{2} \beta_{1}{ }^{\text {high }} \mathrm{CD} 44^{+}$represent typical CSCs in primary $\mathrm{PCa}$ tissues. However, we observed that there were few
$\mathrm{CD} 133^{+} \mathrm{CD} 44^{+}$cells detected in the $5 \mathrm{PCa}$ cell lines examined (Fig. 1A). Therefore, we used SP sorting to isolate stem-like cells (Fig. 1B), and found that although almost no SP cells were detected in the PC-3 cells, we were able to obtain SP cells from each of the other 4 cell lines. The different percentages of SP cells were $0.15 \pm 0.02 \%$ in Du145, $0.6 \pm 0.07 \%$ in IA8, $0.8 \pm 0.1 \%$ in $\mathrm{LNCaP}$ and $2.0 \pm 0.4 \%$ in TSU-PrL cells.

SP cells from the IA8, LNCaP and TSU-PrL cell lines sustained holoclone growth and formed characteristic compact round clones, whereas most NSP cells exhibited elongated or flattened shapes and grew in the pattern of a scattered para- 
A
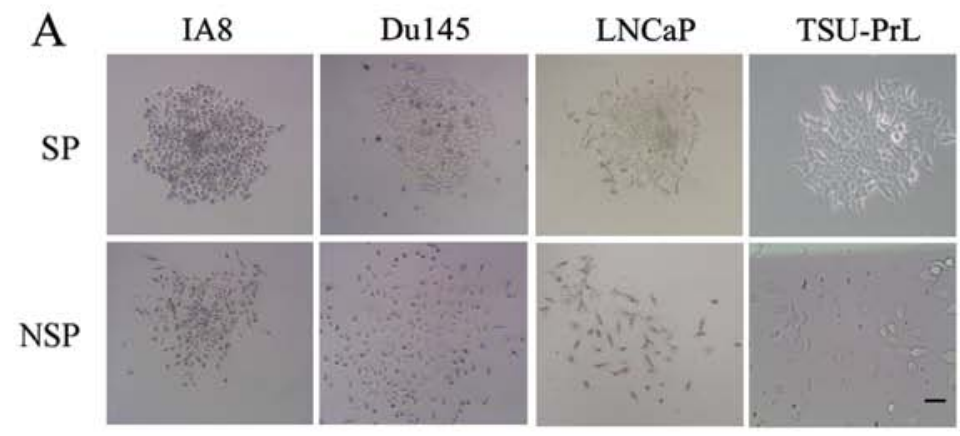

B
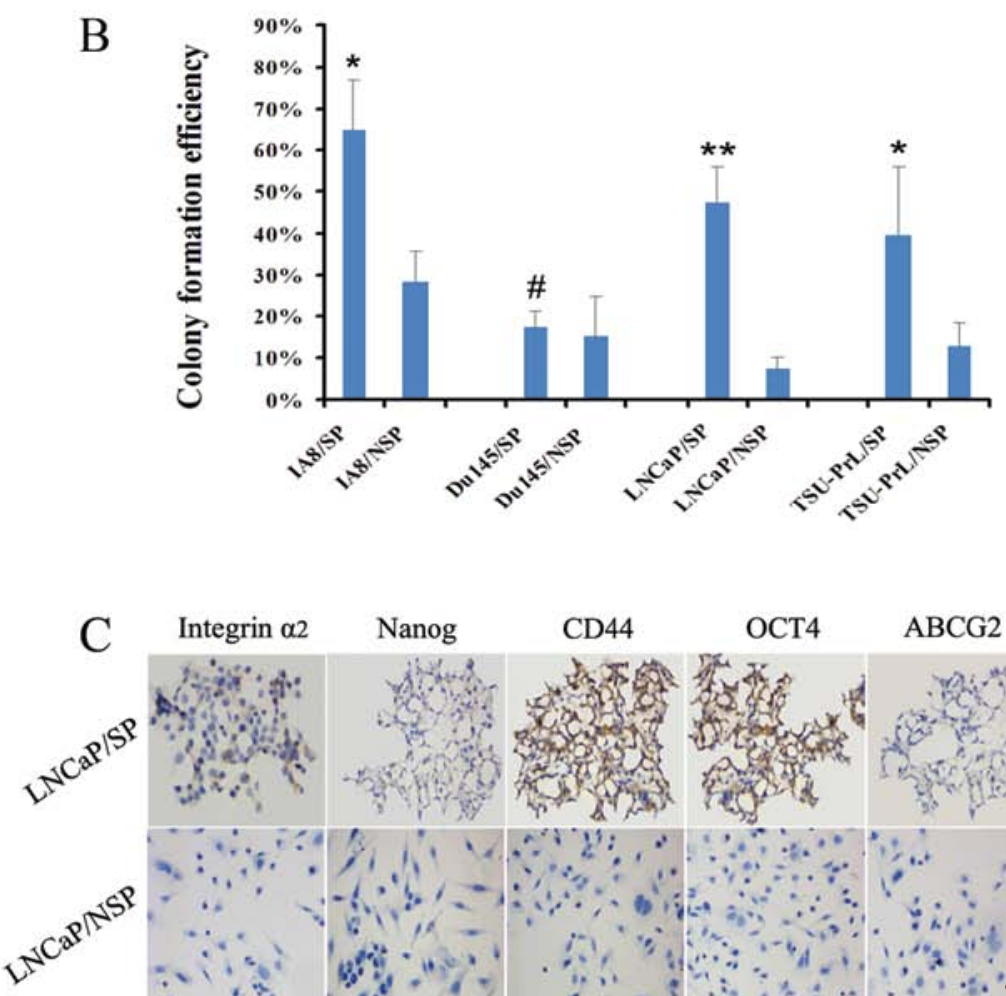

Nanog

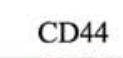

OCT4

ABCG2
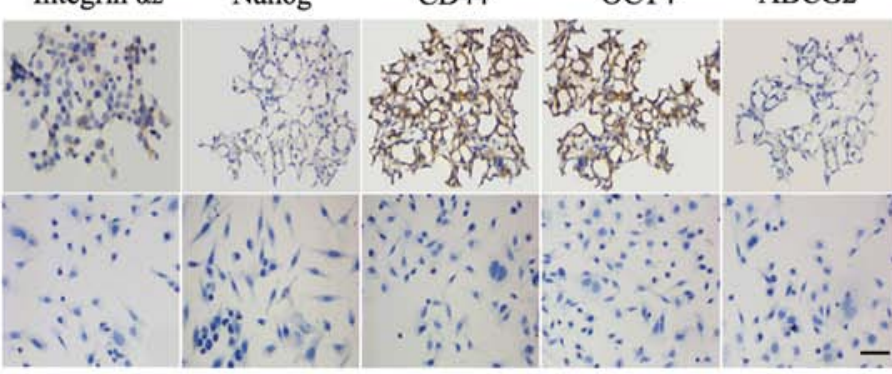

$\mathrm{E}$
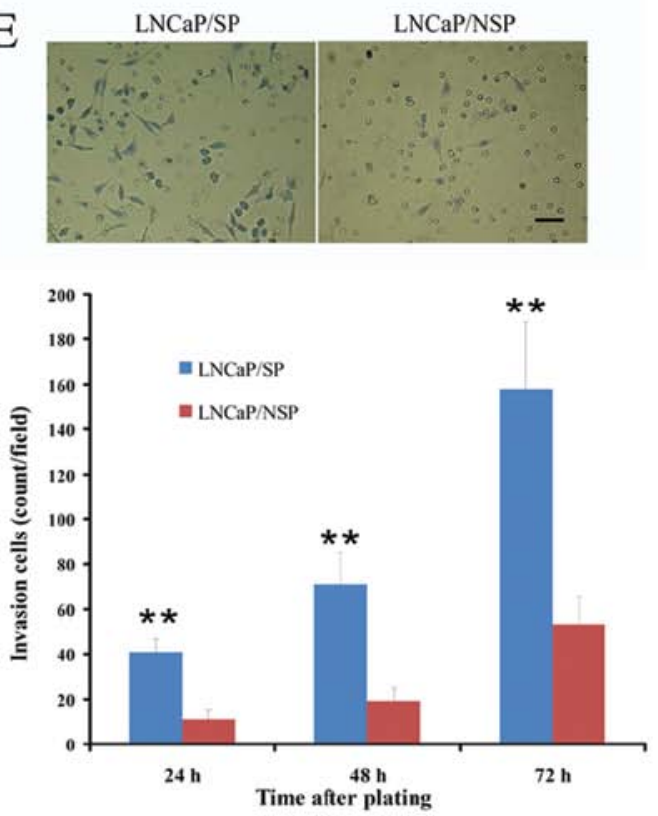

Figure 2. Identification of stem cell properties in LNCaP/SP cells in vitro. (A) SP and NSP cells from the IA8, LNCaP and TSU-PrL cell lines exhibited completely different growth patterns after plating at low density and continuous culture for 1-3 weeks. Most of the SP cells sustained a holoclone growth and formed compact round colonies, whereas most NSP cells grew in a scattered pattern as elongated or flattened cells. (B) The colony formation efficiency of SP cells from the IA8, LNCaP and TSU-PrL cell lines was significantly greater than that of the homologous NSP cells. However, SP cells in the Du145 cell line were no more clonogenic than the NSP cells. (C) Immunostaining analysis indicated that LNCaP/SP cells were specifically positive for stem-cell property marker expression (integrin $\alpha 2$, Nanog, CD44, OCT4 and ABCG2), when compared with the LNCaP/NSP cells. In vitro, LNCaP/SP cells exhibited a significantly higher rate of (D) proliferation and (E) invasion than LNCaP/NSP cells. Scale bar, $50 \mu \mathrm{m} .{ }^{*} \mathrm{P}>0.05,{ }^{*} \mathrm{P}<0.05$ and ${ }^{* *} \mathrm{P}<0.01$ for SP cells compared with NSP cells.

clone (Fig. 2A). SP cells in the Du145 cell line also grew as a tight holoclone, but they were no more clonogenic than their NSP counterparts.

The colony formation efficiency (CFE) (Fig. 2B) of the Du145/SP cells was not significantly greater than that of the Du145/NSP cells (17.4 \pm 10.1 vs. $15.1 \pm 11.7 \%$; P>0.05). However, the CFE of IA8/SP cells was 2.3-fold greater than that of the IA8/NSP cells $(64.6 \pm 12.2$ vs. $28.4 \pm 19.3 \%$; $\mathrm{P}<0.05)$, the CFE of the LNCaP/SP cells was 6.5 -fold greater than that of the LNCaP/NSP cells $(47.2 \pm 8.6$ vs. $7.3 \pm 5.9 \% ; \mathrm{P}<0.01)$ and the CFE of the TSU-PrL/SP cells was 3.1-fold greater than that of the TSU-PrL/NSP cells (39.4 \pm 16.3 vs. $12.7 \pm 6.1 \%$; $\mathrm{P}<0.05)$. These data highlight the stemness-associated clonogenic ability of SP cells derived from the LNCaP, IA8 and TSU-PrL cell lines.

In a previous study we confirmed that $\mathrm{LNCaP}$ is an EMT-negative (epithelial-type) cell line; whereas IA8 and TSU-PrL are EMT-positive (mesenchymal-type) cell lines (14). We further assessed the stemness-associated molecular characteristics in the LNCaP/SP cells in order to collect EMT-negative stem-like cells for EMT induction trials. Compared with LNCaP/NSP, LNCaP/SP cells displayed specific positive expression of stemness markers in immunostaining detection, including integrin $\alpha 2, \mathrm{Nanog}, \mathrm{CD} 44$ and OCT4 (Fig. 2C). 

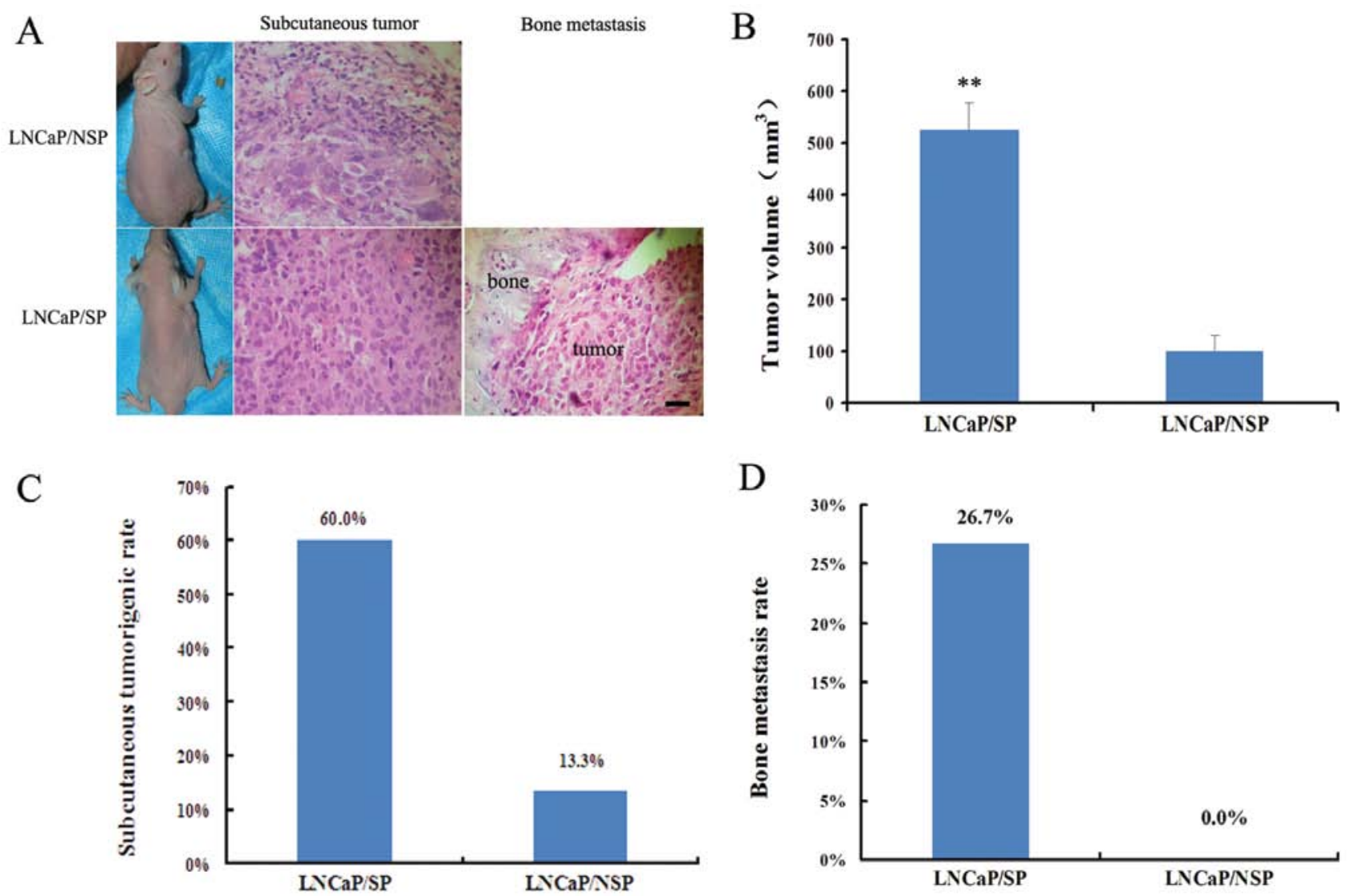

Figure 3. Identification of stem-like cell properties of LNCaP/SP cells in vivo. (A) LNCaP/SP and LNCaP/NSP cells both generated macroscopic tumors following subcutaneous injection in nude mice. H\&E staining verified the presence of tumor cells in subcutaneous masses (produced by these two types of cells) and bone tissues (injected by $\mathrm{LNCaP} / \mathrm{SP}$ cells). $\mathrm{LNCaP} / \mathrm{SP}$ cells generated subcutaneous tumors with a greater volume than tumors derived from $\mathrm{LNCaP} /$ NSP cells (B), and were also associated with a higher rate of (C) tumor occurrence and (D) bone metastasis when compared to LNCaP/NSP cells. ${ }^{* *} \mathrm{P}<0.01 \mathrm{for}$ $\mathrm{LNCaP/SP}$ cells compared with LNCaP/NSP cells.

MTT trials showed that the doubling time of LNCaP/SP cells was shorter than that of the LNCaP/NSP cells ( 2 vs. 3 days) (Fig. 2D), which indicated that the LNCaP/SP cells proliferated markedly faster. Additionally, the number of cells that digested Matrigel and migrated through the filter with $8-\mu \mathrm{m}$ pores was significantly higher in the $\mathrm{LNCaP} / \mathrm{SP}$ group than the migratory cell number in the LNCaP/NSP group at 24 , 48 and $72 \mathrm{~h}$ after plating (Fig. 2E). These results suggest that stem-like cells (LNCaP/SP) have a much higher proliferative and invasive potential than their bulk counterparts ( $\mathrm{LNCaP} /$ NSP) in vitro.

The in vivo models (Fig. 3A) indicated that the tumor volume of the LNCaP/SP models was 5.2-fold greater than the tumor volume in the $\mathrm{LNCaP} / \mathrm{NSP}$ models $(526 \pm 53$ vs. $100 \pm 29 \mathrm{~mm}^{3}$; P<0.01) (Fig. 3B). LNCaP/SP cells also showed a noticeably higher rate of tumor incidence (60 vs. $13.3 \%$ ) (Fig. 3C) and bone metastasis (26.7 vs. 0\%; Fig. 3D) when compared with the LNCaP/NSP cells. Thus, collectively, $\mathrm{LNCaP/SP}$ cells appeared to represent a sub-population of stem-like cells in the LNCaP cell line which display a stemness phenotype.

Comparison of EMT activity in LNCaP/SP and LNCaP/NSP cells. To confirm that transfection of HIF-1 $\alpha$ was functional, we firstly analyzed the expression of HIF-1 $\alpha$ and its downstream proteins (Glut-1 and VEGF) in transfected cells. Western blot analysis indicated that all three proteins were positively expressed in the LNCaP/HIF- $1 \alpha / \mathrm{SP}$ and LNCaP/HIF-1 $\alpha / \mathrm{NSP}$ cells (Fig. 4A). EMT-phenotype analysis showed that although LNCaP/SP and LNCaP/NSP cells were both typical epithelialtype cells, LNCaP/HIF-1 $\alpha /$ SP cells acquired a relatively complete mesenchymal-type with no evidence of expression of epithelial markers, E-cadherin or CK18, nor aberrant expression of mesenchymal proteins, vimentin, $\mathrm{N}$-cadherin, fibronectin, cathepsin D, MMP-2 and uPAR (Fig. 4B). By contrast, LNCaP/HIF-1 $\alpha /$ NSP cells displayed characteristics of a partial mesenchymal-type with weak expression of vimentin and cathepsin D and loss of CK18 (Fig. 4B).

In the Transwell invasion assays, the number of LNCaP/ HIF-1 $\alpha /$ SP cells penetrating through the Matrigel-coated filter was noticeably higher than the number of LNCaP/HIF-1 $\alpha / \mathrm{NSP}$ cells after plating for 24, 48 and $72 \mathrm{~h}$ (Fig. 4C). MTT experiments showed that the doubling time of LNCaP/HIF-1 $\alpha / \mathrm{SP}$ cells was shorter than that of LNCaP/HIF-1 $\alpha / \mathrm{NSP}$ cells ( 2 vs. 3 days) (Fig. 4D).

Transfected cells were used in xenograft experiments to validate the influence of the EMT phenotype on tumor growth and distant metastases. Pathological examination verified that both $\mathrm{LNCaP} / \mathrm{HIF}-1 \alpha / \mathrm{SP}$ and LNCaP/HIF-1 $\alpha / \mathrm{NSP}$ cells generated macroscopic tumors subcutaneously in nude mice, but only LNCaP/HIF-1 $\alpha / \mathrm{SP}$ cells resulted in bone metastasis (Fig. 4E). 

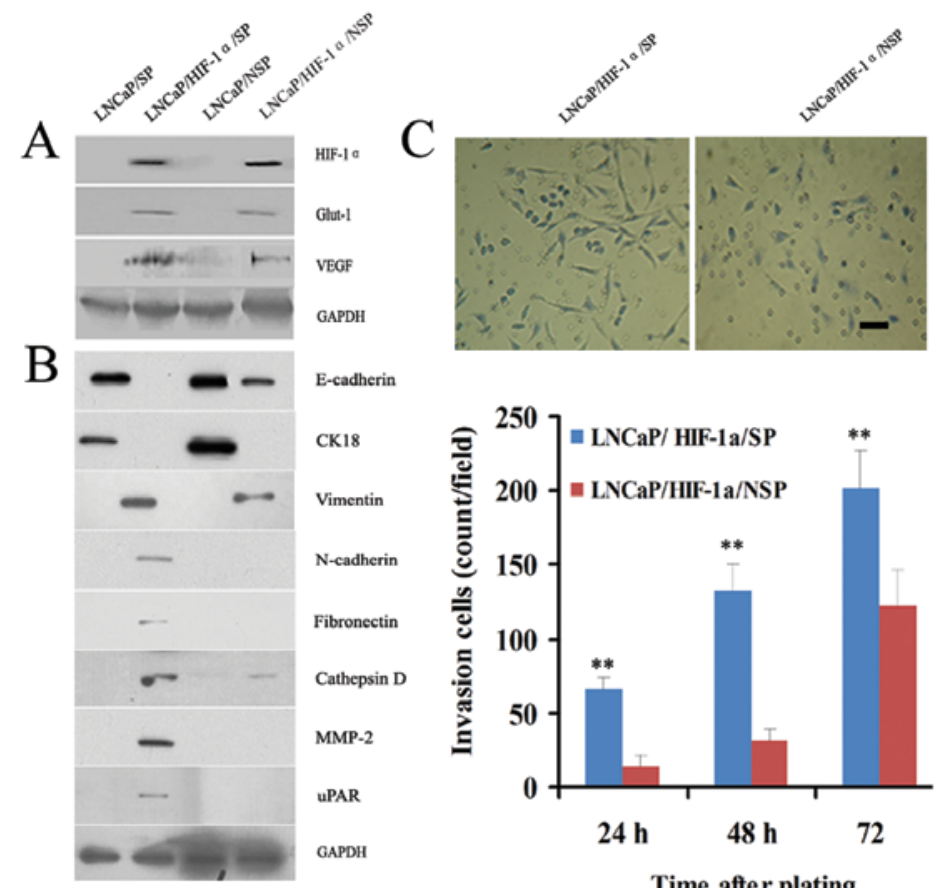

\section{$\mathrm{D}$}
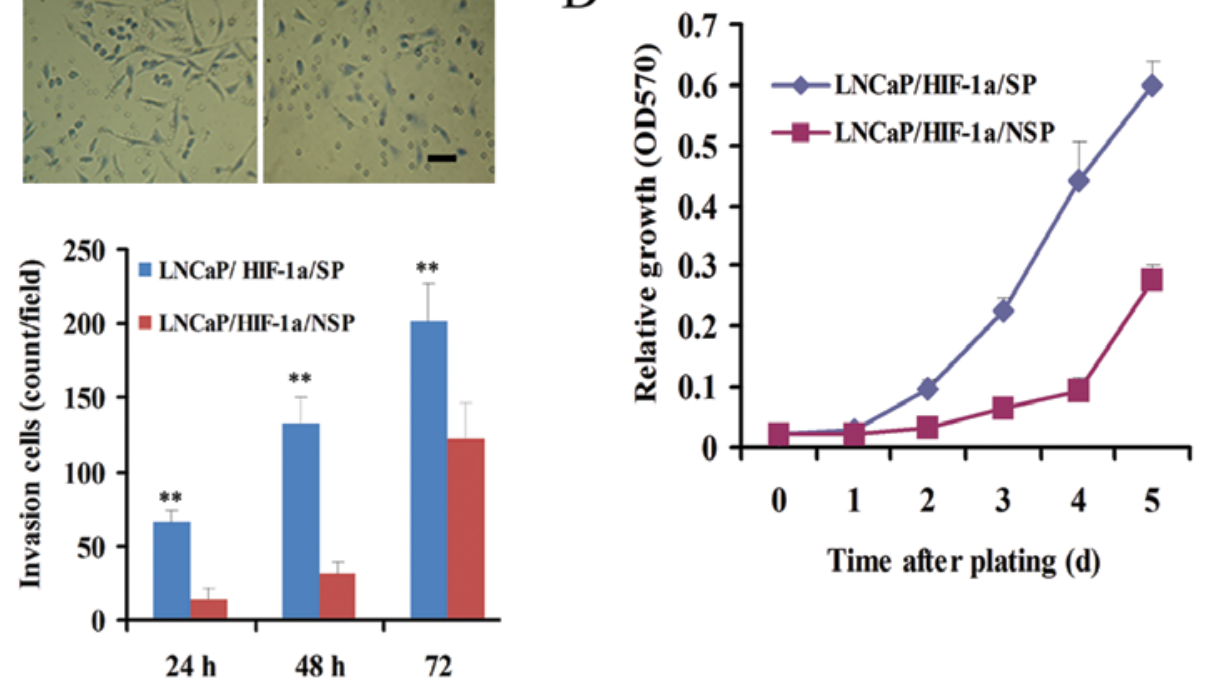

Time after plating (d)

Time after plating

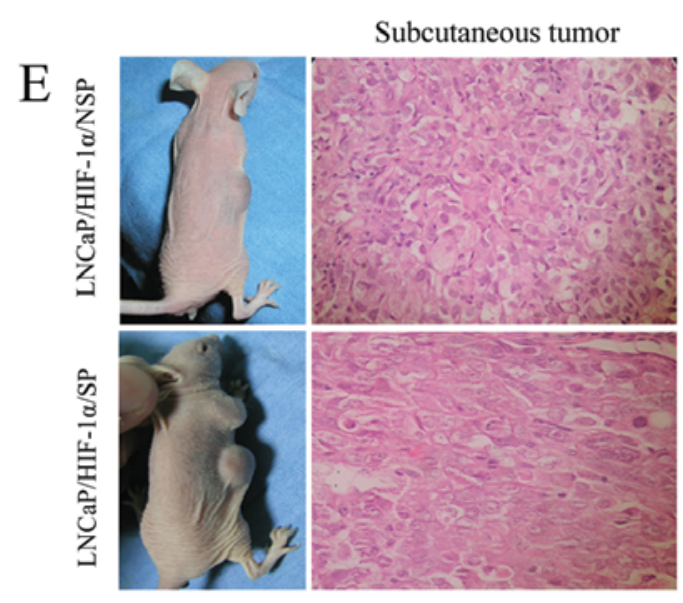

Bone metastasis
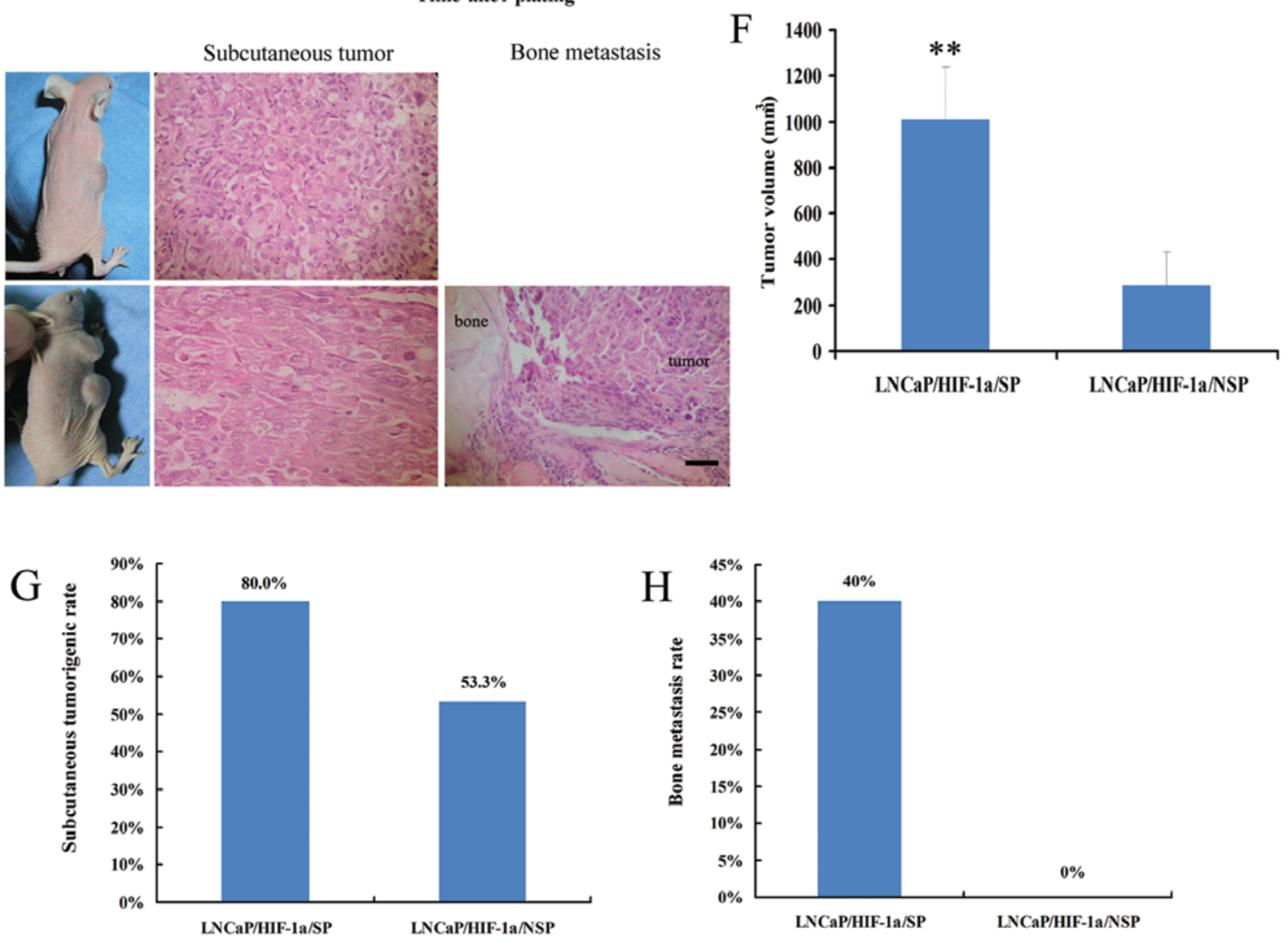

Figure 4. Comparison of EMT activity between LNCaP/SP and LNCaP/NSP cells. (A) Western blot analysis confirmed the definitive expression of HIF-1 $\alpha$ and its two important downstream proteins, Glut-1 and VEGF, in stably transfected LNCaP/HIF-1 $\alpha / \mathrm{SP}$ and LNCaP/HIF-1 $\alpha / \mathrm{NSP}$ cells. (B) Although the LNCaP/SP and LNCaP/NSP cell lines were both epithelial phenotypes, LNCaP/HIF-1 $\alpha /$ SP cells typically acquired a mesenchymal phenotype, and LNCaP/HIF-1 $\alpha /$ NSP cells displayed weak mesenchymal characteristics. (C) Representative fields of cells that digested Matrigel and migrated through the chemotaxis filter were photographed after $48 \mathrm{~h}$ incubation in Transwells. The number of LNCaP/HIF-1 $\alpha / \mathrm{SP}$ cells penetrating through the filter was markedly higher than the number of LNCaP/HIF-1 $\alpha / \mathrm{NSP}$ cells after 24, 48 and $72 \mathrm{~h}$ of incubation. (D) LNCaP/HIF-1 $\alpha / \mathrm{SP}$ cells propagated much faster than LNCaP/HIF-1 $\alpha / \mathrm{NSP}$ cells when plated at low density. (E) After subcutaneously injection, LNCaP/HIF-1 $\alpha / \mathrm{SP}$ and LNCaP/HIF-1 $\alpha / \mathrm{NSP}$ cells both formed neoplasias, while bone metastasis was only observed in the $\mathrm{LNCaP} / \mathrm{HIF}-1 \alpha / \mathrm{SP}$ xenograft models. Further analysis showed that injection of LNCaP/HIF-1 $\alpha / \mathrm{SP}$ cells generated tumors of much greater volume $(\mathrm{F})$, and at a much higher rate of tumorigenesis $(\mathrm{G})$, than the LNCaP/HIF-1 $\alpha / \mathrm{NSP}$ cells. $(\mathrm{H})$ The rate of bone metastasis in the LNCaP/HIF-1 $\alpha /$ SP group was also noticeably higher than that in the LNCaP/HIF-1 $\alpha /$ NSP group, which produced no visible bone metastases. Scale bar, $50 \mu \mathrm{m} .{ }^{* *} \mathrm{P}<0.01$ for LNCaP/HIF-1 $\alpha /$ SP models compared with LNCaP/HIF-1 $\alpha /$ NSP models. 


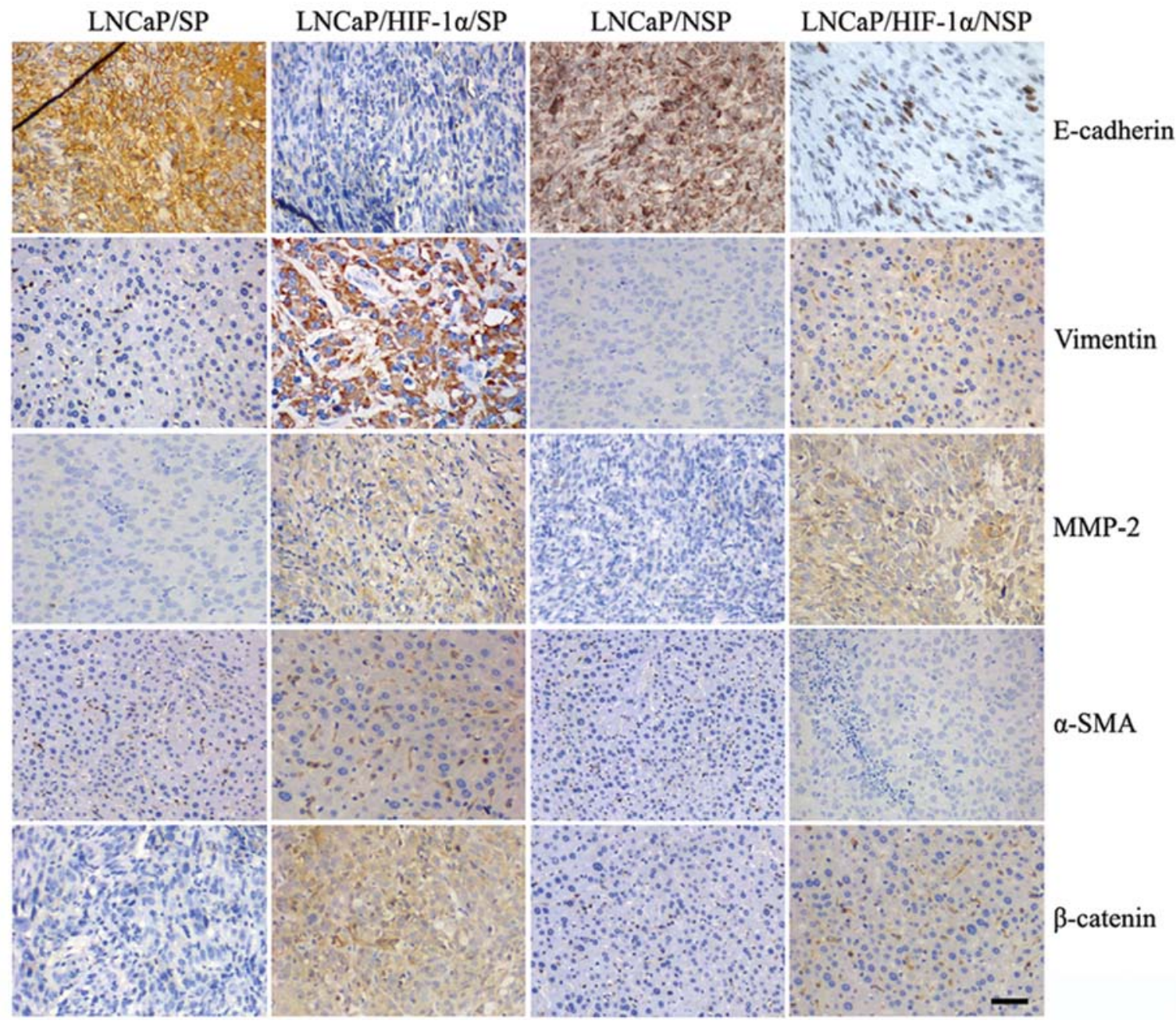

Figure 5. EMT phenotype of the subcutaneous tumors. Subcutaneous tumor tissues generated by LNCaP/SP and LNCaP/NSP cells were both epithelial-like and both expressed E-cadherin. Conversely, tumor tissues derived from the LNCaP/HIF-1 $\alpha / \mathrm{SP}$ cells were typically mesenchymal-like and were characterized by loss of E-cadherin and expression of mesenchymal markers (vimentin, MMP-2, $\alpha$-SMA and $\beta$-catenin). Xenografts derived from the LNCaP/HIF-1 $\alpha / \mathrm{NSP}$ cells also showed mesenchymal-type characteristics with abundant expression of MMP-2 and weak expression of $\beta$-catenin and vimentin. Scale bar, $50 \mu \mathrm{m}$.

Further analysis demonstrated that the volume of subcutaneous tumors produced from the $\mathrm{LNCaP} / \mathrm{HIF}-1 \alpha / \mathrm{SP}$ cells was 3.5-fold greater than that of tumors produced from the LNCaP/HIF-1 $\alpha / \mathrm{NSP}$ cells $\left(1,008 \pm 230\right.$ vs. $288 \pm 145 \mathrm{~mm}^{3}$; $\mathrm{P}<0.01$ ) (Fig. 4F). The rate of tumorigenesis resulting from LNCaP/HIF-1 $\alpha / \mathrm{SP}$ cells was also much higher than that noted with LNCaP/HIF-1 $\alpha /$ NSP cells (80 vs. 53\%) (Fig. 4G).

We also demonstrated that $\mathrm{LNCaP} / \mathrm{HIF}-1 \alpha / \mathrm{SP}$ cells were able to induce conspicuous bone metastasis, whereas LNCaP/HIF-1 $\alpha / \mathrm{NSP}$ did not result in bone metastasis at the experimental end point (40 vs. 0\%) (Fig. 4H). These findings suggest that $\mathrm{LNCaP} / \mathrm{SP}$ cells are more likely to acquire mesenchymal and aggressive phenotypes than LNCaP/NSP cells.

Identification of the EMT phenotype in the PCa xenograft tumors. Immunohistochemical staining indicated that xenografted tumors generated by LNCaP/SP and LNCaP/NSP cells both displayed characteristics of an epithelial phenotype with expression of E-cadherin and loss of mesenchymal markers (vimentin, MMP-2, $\alpha$-SMA and $\beta$-catenin) (Fig. 5). By contrast, tumors generated by LNCaP/HIF-1 $\alpha / \mathrm{SP}$ cells displayed a strong mesenchymal phenotype characterized by loss of E-cadherin and acquisition of mesenchymal markers. Xenografts from the LNCaP/HIF-1 $\alpha /$ NSP models also showed mesenchymal phenotype because of their abundant expression of MMP-2 and weak expression of $\beta$-catenin and vimentin, even though they showed low expression of E-cadherin. These findings indicated that xenograft tumor tissues produced by the injection $\mathrm{LNCaP} / \mathrm{SP}$ cells were suitable for isolating stemlike cells with an epithelial phenotype.

Evidence for stem-like cells in human PCa xenograft tissues. Tumor cells in subcutaneous xenografts produced from LNCaP/SP cells were cultured and used for secondary SP sorting. The isolated SP cells, and their non-SP counterparts were referred to as $\mathrm{LNCaP} / \mathrm{SP} 2$ and $\mathrm{LNCaP} / \mathrm{NSP} 2$, respectively.

FACS indicated that $\mathrm{LNCaP} / \mathrm{SP} 2$ cells represented $\sim 1.1 \pm 0.3 \%$ of the total cell population (Fig. $6 \mathrm{~A}$ ). These cells grew in a typical holoclone pattern and produced much higher numbers in regards to CFE than LNCaP/NSP2 cells (68.35 \pm 9.67 vs. $10.60 \pm 3.4 \%$; $\mathrm{P}<0.01)$ (Fig. 6B). Stemness markers, including ABCG2, OCT4, integrin $\alpha 2$, Nanog and 

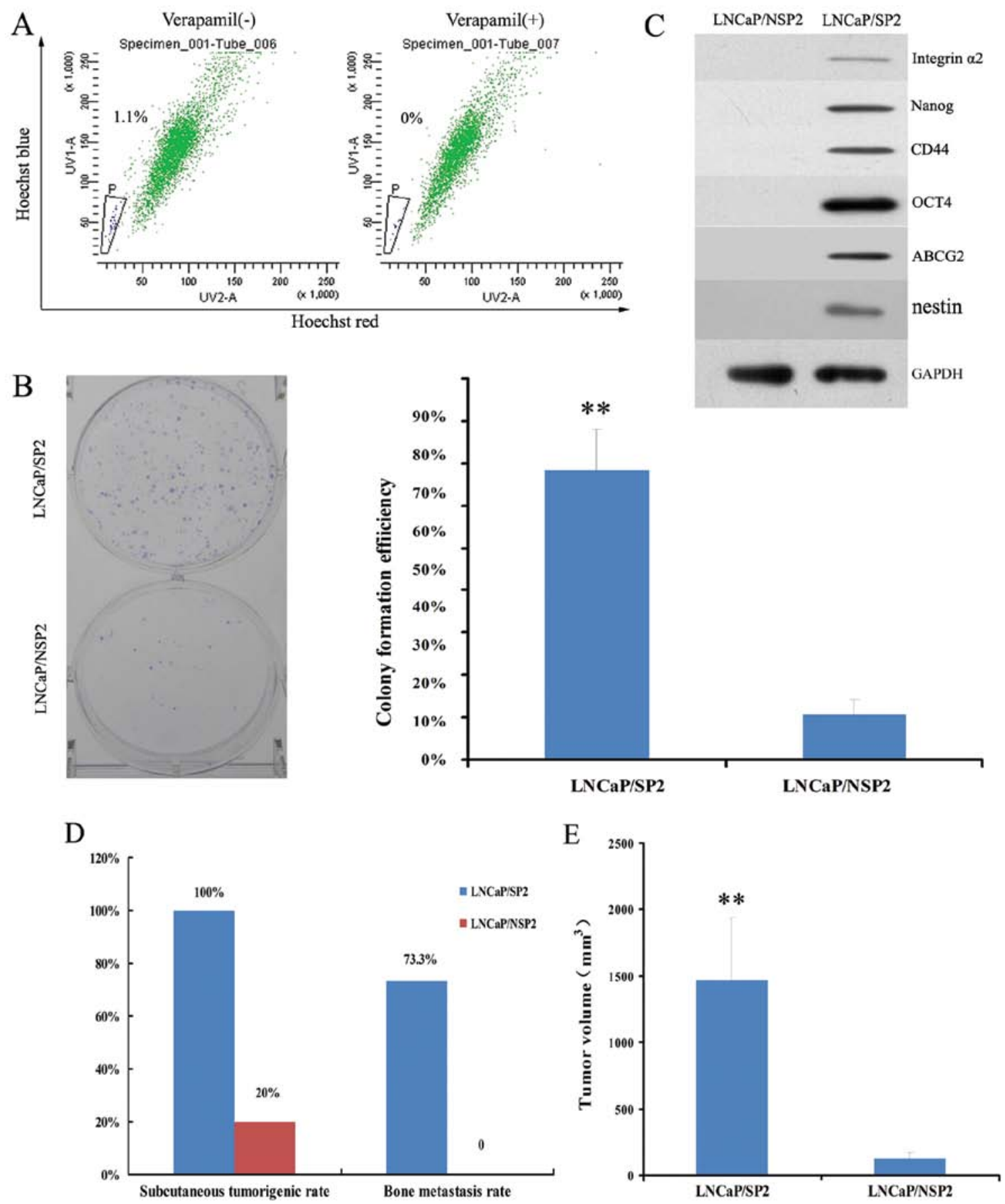

Figure 6. Identification of stem-like cells in the prostate cancer xenograft tissues. (A) LNCaP/SP2 cells were sorted from xenograft tumors and $\sim 1.1 \%$ were produced by $\mathrm{LNCaP} / \mathrm{SP}$ cells. In vitro assays showed that $\mathrm{LNCaP} / \mathrm{SP} 2$ cells displayed a typical holoclonal growth pattern (B), and positive expression of stemness markers (C). (D) Further xenograft experiments showed that the rates of subcutaneous tumorigenesis and bone metastasis in the LNCaP/SP2 group were both much higher than those in the LNCaP/NSP2 group. (E) Additionally, LNCaP/SP2 cells formed subcutaneous tumors with a significantly larger volume than the tumors generated from the LNCaP/NSP2 cells. ${ }^{* *} \mathrm{P}<0.01$ for LNCaP/SP2 compared with LNCaP/NSP2 models.

CD44, were positively expressed in the LNCaP/SP2 cells and negatively expressed in the LNCaP/NSP2 cells (Fig. 6C).

Additionally, LNCaP/SP2 cells exhibited a much higher rate of subcutaneous tumorigenesis (100 vs. $20 \%$ ) and bone metastasis (73.3 vs. $0 \%)$ in the nude mouse xenograft models when compared with the LNCaP/NSP2 cells (Fig. 6D). This was characterized by a much greater tumor volume $(1470 \pm 470$ vs. $126 \pm 48 \mathrm{~mm}^{3} ; \mathrm{P}<0.01$ ) (Fig. $6 \mathrm{E}$ ). These observations suggest that $\mathrm{LNCaP} / \mathrm{SP} 2$ cells represent a stem-like cell subpopulation of LNCaP/SP cells in the PCa xenograft tissues.
Comparison of the EMT activity between LNC $\alpha P / S P 2$ and LNCaP/NSP2 cells. Functional transfection of LNCaP/HIF-1 $\alpha / \mathrm{SP} 2$ cells with HIF-1 $\alpha$ resulted in loss of epithelial markers (E-cadherin and CK18) and acquisition of mesenchymal markers (vimentin, N-cadherin, fibronectin, cathepsin D, MMP-2 and uPAR) (Fig. 7A). LNCaP/HIF-1 $\alpha /$ NSP2 cells showed a partial mesenchymal phenotype, with loss of epithelial proteins, E-cadherin and CK18, and sporadic expression of mesenchymal proteins, cathepsin D and MMP-2 (Fig. 7B). 

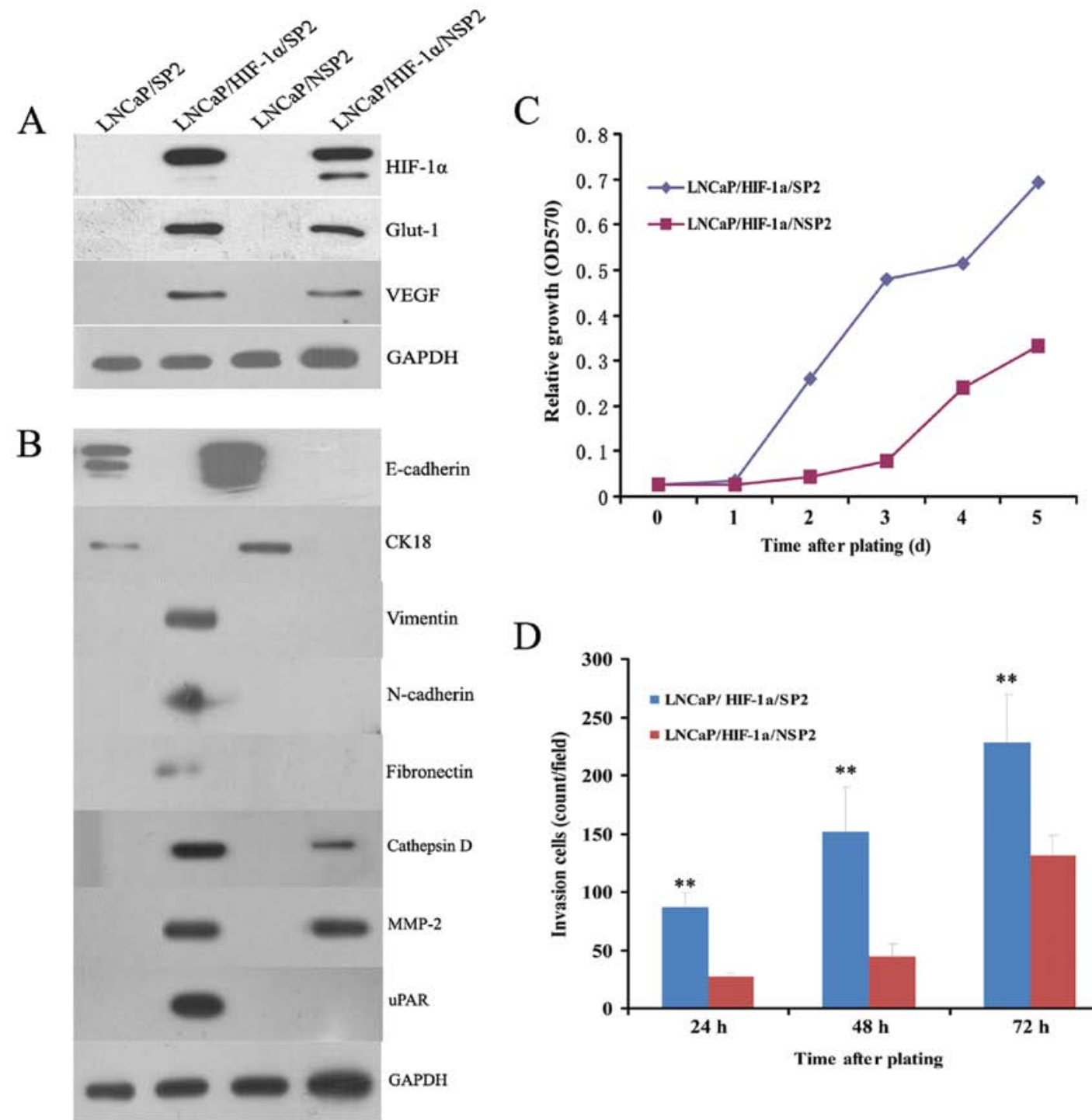

$\mathrm{D}$
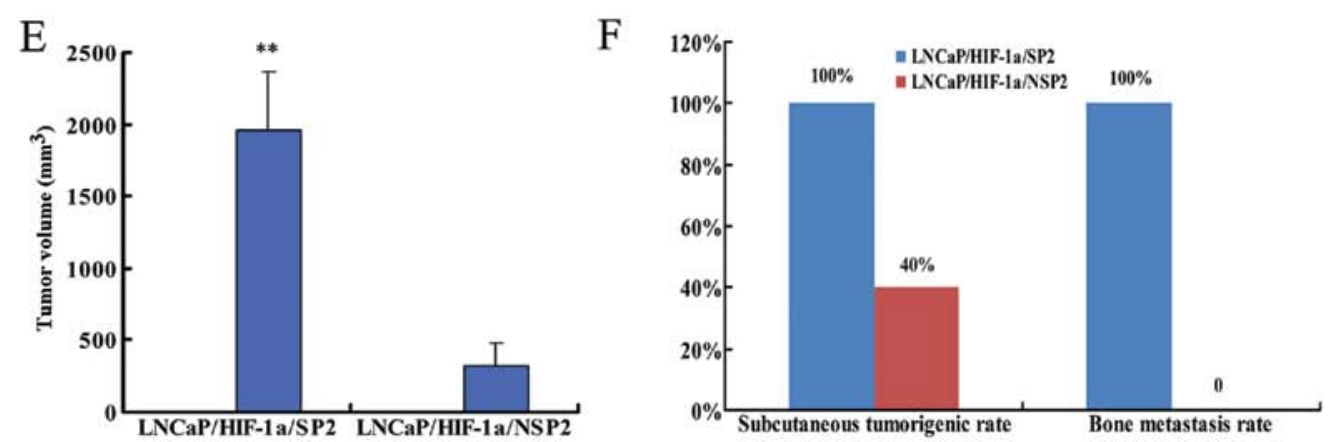

Figure 7. Comparison of EMT activity between LNCaP/SP2 and LNCaP/NSP2 cells. (A) Western blot analysis demonstrated functional expression of HIF-1 $\alpha$ in stably transfected LNCaP/HIF-1 $\alpha /$ SP2 and LNCaP/HIF-1 $\alpha /$ NSP2 cells. (B) Following induction by HIF-1 $\alpha$, LNCaP/HIF-1 $\alpha /$ SP2 cells displayed a typically mesenchymal phenotype, whereas LNCaP/HIF-1 $\alpha / \mathrm{NSP} 2$ cells only expressed a partially mesenchymal phenotype. In vitro assays showed that LNCaP/HIF-1 $\alpha /$ SP2 cells exhibited (C) markedly stronger proliferation and (D) invasive capability than LNCaP/HIF-1 $\alpha /$ NSP2 cells. (E) LNCaP/HIF-1 $\alpha / S P 2$ cells generated greater tumor mass than LNCaP/HIF-1 $\alpha / \mathrm{NSP} 2$ cells in the nude mouse models. (F) The rates of subcutaneous tumorigenesis and bone metastasis in the LNCaP/HIF-1 $\alpha / \mathrm{SP} 2$ group were also higher than these values in the LNCaP/HIF-1 $\alpha / \mathrm{NSP} 2$ group. ${ }^{* *} \mathrm{P}<0.01$ for the LNCaP/HIF-1 $\alpha / \mathrm{SP} 2$ model compared with the LNCaP/HIF-1 $\alpha / \mathrm{NSP} 2$ model.

LNCaP/HIF-1 $\alpha /$ SP2 cells displayed markedly higher proliferative ability than LNCaP/HIF-1 $\alpha / \mathrm{NSP} 2$ cells. The doubling time of $\mathrm{LNCaP} / \mathrm{HIF}-1 \alpha / \mathrm{SP} 2$ cells was shorter than that of the LNCaP/HIF-1 $\alpha / \mathrm{NSP} 2$ cells (2 vs. 4 days) (Fig. 7C).

The number of LNCaP/HIF-1 $\alpha / \mathrm{SP} 2$ cells that penetrated through the Matrigel filter after 24, 48 and $72 \mathrm{~h}$ was notice- ably higher than the number of LNCaP/HIF-1 $\alpha / \mathrm{NSP} 2$ cells, respectively (Fig. 7D).

Following subcutaneous injection in nude mice, LNCaP/HIF-1 $\alpha / \mathrm{SP} 2$ cells exhibited conspicuously higher tumorigenic and metastatic ability than the LNCaP/ HIF-1 $\alpha /$ NSP2 cells (Fig. 7E and F). Taken together, these find- 
ings imply that stem-like SP cells from PCa xenograft tissues possess more active potential than their bulk counterparts to undergo EMT. This result was consistent with the findings in the stem-like SP cells from the PCa cell lines.

\section{Discussion}

SP cells are a small subset of cells characterized by exclusion of Hoechst 33342 DNA binding dye. Breast cancer-resistant protein-1 (BCRP1 or ABCG2) has been identified as a crucial protein involved in maintaining the SP phenotype. A large body of evidence indicates that CSCs are enriched in SP cells in several types of solid carcinomas (15-17). In the present study, we investigated the underlying relationship between EMT phenomenon and prostate CSCs, replaced by SP cells.

Reports indicate that the acquisition of the EMT phenotype and induction of the stemness phenotype are highly interrelated during tumor progression (18). Many experiments support a 'twinborn relationship' between EMT and CSCs based on common molecular mechanisms shared by EMT development and CSC generation. For example, two evolutionarily conserved families, miR-200 and let-7, have been shown to play a dual role in controlling EMT processes by direct targeting E-box binding protein ZEB1 and ZEB2 (19-21). They have also been shown to affect the self-renewal capacity and stem-like cell signatures of breast cancer cells by regulating the expression of BMI1 $(22,23)$. It has also been proposed that several nuclear transcription factors, including $\beta$-catenin, ESE3/EHF and FoxM1, may bidirectionally regulate the EMT process and the stemness phenotype (24-26). The signaling pathway mediated by IKK $\beta / \mathrm{I} \kappa \mathrm{B} \alpha / \operatorname{RelA}$, uPAR and Notch-1 have been found to be synchronously involved in the activation of the EMT process and the acquisition of a stemness phenotype during tumor progression (27-29).

Other studies describe a 'parent-child relationship' between EMT and CSCs based on the observation that EMT promotes the generation of a stemness phenotype. In a mammary tumor progression model, the acquisition of stemness characteristics in breast epithelial cells was found to be driven by EMT induction following the activation of the Ras-MAPK pathway (30). Additional research demonstrated that breast cancer cells that have undergone EMT provide a rich source of stem-like cancer cells. In these experiments, the induction of EMT in differentiated immortalized human mammary epithelial cells resulted in acquisition of the $\mathrm{CD} 44^{+} / \mathrm{CD} 24^{-}$stem cell phenotype (31). Additionally, our previous study also found that the EMT process triggered by HIF-1 $\alpha$ significantly promoted the stem-like SP cell proportion in human thyroid cancer FTC133 cells (32).

In the present study, we propose a novel 'parasite-host relationship' between EMT and CSCs. This is based on the findings of Biddle et al that a population of CSCs with CD44 ${ }^{\text {high }} \mathrm{ESA}^{\text {low }}$ phenotype undergo EMT in squamous cell carcinoma (33). We further compared differences in EMT initiated by HIF-1 $\alpha$ in cancer stem-like cells and bulk population PCa cells, and confirmed that stem-like cells are susceptible to EMT.

Previous published findings (31) indicate that putative $\mathrm{CD} 44^{+} / \mathrm{CD} 24^{-}$CSCs isolated from neoplastic human breast tissues express high levels of a specific mRNA that encodes the EMT-associated markers Snail1, Snail2 and Twist. When compared with parental cells (34), stemness spheroid-derived head and neck squamous cell carcinoma cell lines showed significantly increased mRNA levels of EMT-related transcription genes (Snail1, Snail2 and Twist), together with increased protein expression of $\alpha$-SMA and vimentin, and decreased protein expression of E-cadherin. Collectivelly, these previously published findings indicate that genetic programs relevant to EMT are significantly activated in stem-like cells. They also indicate that CSCs not only represent the prerequisite for the EMT process, but that they may also form a reservoir of cells responsible for achieving EMT.

The interrelationship between CSCs and EMT phenotypic cells represents a potentially promising new therapeutic target. A growing body of evidence demonstrates a strong link between the biology of EMT and CSCs in terms of the sequences and compositions of miRNA molecules, suggesting that targeting these miRNAs may provide a novel therapeutic strategy. Other researchers (35) have demonstrated that antagonism of miR-21 reverses the EMT and CSC phenotype by inactivating the AKT/ERK1/2 pathways, and thereby relieves the aggressiveness of breast cancer. Moreover, an in vivo study (36) showed that miR145 reduces xenograft tumor growth and metastasis, sensitizes tumors to chemoradiotherapy, and prolongs patient survival, by inhibiting the lung adenocarcinoma cell phenotype of EMT and stemness. This was thought to be achieved by regulating Oct4/Sox2/Fascin1, Tcf4 and Wnt5a.

It is believed that miR-34a plays a critical regulatory role in pancreatic cancer progression by regulating CSC characteristics. Experimental evidence indicates that re-expression of miR-34 $\alpha$ in human pancreatic CSCs not only eliminates CSC characteristics, but also retards in vitro migration and invasion of CSCs and enhances the CSC response to chemotherapy (37). $\mathrm{CDF}$ is a novel analogue of curcumin, which may also play a role as a therapeutic marker, as it has been shown to attenuate CSC characteristics and suppress CSC function by targeting an EZH2-miRNA regulatory circuit. These characteristics resulted in inhibition of pancreatic tumor growth and a reduction in aggressiveness in vivo $(38,39)$.

In summary, our comparison of EMT activity in stem-like cells and their counterparts in PCa support the notion that prostate stem-like cells play a representative 'cell carrier' role in EMT progression. This finding may help in the development of more effective strategies for targeting stemness and EMT, that may in turn help to suppress local tumor relapse and minimize distant metastatic spread.

\section{Acknowledgements}

This project was supported by the National Natural Science Foundation of China (NSFC no. 30700968 and 30901725).

\section{References}

1. Thiery JP, Acloque H, Huang RY and Nieto MA: Epithelialmesenchymal transitions in development and disease. Cell 139: 871-890, 2009.

2. Yang MH, Wu MZ, Chiou SH, Chen PM, Chang SY, Liu CJ, Teng SC and Wu KJ: Direct regulation of TWIST by HIF-1a promotes metastasis. Nat Cell Biol 10: 295-305, 2009. 
3. Gjerdrum C, Tiron C, Hoiby T, Stefansson I, Haugen H, Sandal T, Collett K, Li S, McCormack E, Gjertsen BT, Micklem DR, Akslen LA, Glackin C and Lorens JB: Axl is an essential epithelial-to-mesenchymal transition-induced regulator of breast cancer metastasis and patient survival. Proc Natl Acad Sci USA 107: 1124-1129, 2010.

4. Kudo-Saito C, Shirako H, Takeuchi T and Kawakami Y: Cancer metastasis is accelerated through immunosuppression during Snail-induced EMT of cancer cells. Cancer Cell 15: 195-206, 2009.

5. Gupta PB, Onder TT, Jiang G, Tao K, Kuperwasser C, Weinberg RA and Lander ES: Identification of selective inhibitors of cancer stem cells by high-throughput screening. Cell 138: 645-659, 2009

6. Skvortsova I, Skvortsov S, Raju U, Stasyk T, Riesterer O, Schottdorf EM, Popper BA, Schiestl B, Eichberger P, Debbage P, Neher A, Bonn GK, Huber LA, Milas L and Lukas P: Epithelialto-mesenchymal transition and c-myc expression are the determinants of cetuximab-induced enhancement of squamous cell carcinoma radioresponse. Radiother Oncol 96: 108-115, 2010.

7. Bandyopadhyay A, Wang L, Agyin J, Tang Y, Lin S, Yeh IT, De $K$ and Sun LZ: Doxorubicin in combination with a small TGF $\beta$ inhibitor: a potential novel therapy for metastatic breast cancer in mouse models. PLoS One 5: e10365, 2010.

8. Lobo NA, Shimono Y, Qian D and Clarke MF: The biology of cancer stem cells. Annu Rev Cell Dev Biol 23: 675-699, 2007.

9. Yu Z, Pestell TG, Lisanti MP and Pestell RG: Cancer stem cells. Int J Biochem Cell Biol 44: 2144-2151, 2012.

10. Kong D, Banerjee S, Ahmad A, Li Y, Wang Z, Sethi S and Sarkar FH: Epithelial to mesenchymal transition is mechanistically linked with stem cell signatures in prostate cancer cells. PLoS One 5: e12445, 2010.

11. Turner $C$ and Kohandel M: Investigating the link between epithelial-mesenchymal transition and the cancer stem cell phenotype: a mathematical approach. J Theor Biol 265: 329-335, 2010.

12. Luo Y, He DL, Ning L, Shen SL, Li L, Li X, Zhau HE and Chung LW: Over-expression of hypoxia-inducible factor-1a increases the invasive potency of $\mathrm{LNCaP}$ cells in vitro. BJU Int 98: 1315-1139, 2006.

13. Collins AT, Berry PA, Hyde C, Stower MJ and Maitland NJ: Prospective identification of tumorigenic prostate cancer stem cells. Cancer Res 65: 10946-10951, 2005.

14. Jiang YG, Luo Y, He DL, Li X, Zhang LL, Peng T, Li MC and Lin YH: Role of Wnt/beta-catenin signaling pathway in epithelial-mesenchymal transition of human prostate cancer induced by hypoxia-inducible factor-1 $\alpha$. Int J Urol 14: 1034-1039, 2007.

15. Yu SC and Bian XW: Enrichment of cancer stem cells based on heterogeneity of invasiveness. Stem Cell Rev 5: 66-71, 2007.

16. Oates JE, Grey BR, Addla SK, Samuel JD, Hart CA, Ramani VA, Brown MD and Clarke NW: Hoechst 33342 side population identification is a conserved and unified mechanism in urological cancers. Stem Cells Dev 18: 1515-1522, 2009.

17. Zhou J, Wang H, Cannon V, Wolcott KM, Song H and Yates C: Side population rather than $\mathrm{CD} 133^{+}$cells distinguishes enriched tumorigenicity in hTERT-immortalized primary prostate cancer cells. Mol Cancer 10: 112, 2011.

18. May CD, Sphyris N, Evans KW, Werden SJ, Guo W and Mani SA: Epithelial-mesenchymal transition and cancer stem cells: a dangerously dynamic duo in breast cancer progression. Breast Cancer Res 13: 202, 2011.

19. Cano A and Nieto MA: Non-coding RNAs take centre stage in epithelial-to-mesenchymal transition. Trends Cell Biol 18 357-359, 2008

20. Gregory PA, Bert AG, Paterson EL, Barry SC, Tsykin A Farshid G, Vadas MA, Khew-Goodall Y and Goodall GJ: The miR-200 family and miR-205 regulate epithelial to mesenchymal transition by targeting ZEB1 and SIP1. Nat Cell Biol 10: 593-601, 2008.

21. Li Y, VandenBoom TG II, Kong D, Wang Z, Ali S, Philip PA and Sarkar FH: Up-regulation of miR-200 and let-7 by natural agents leads to the reversal of epithelial-to-mesenchymal transition in gemcitabine-resistant pancreatic cancer cells. Cancer Res 69 6704-6712, 2009.

22. Wellner U, Schubert J, Burk UC, Schmalhofer O, Zhu F, Sonntag A, Waldvogel B, Vannier C, Darling D, zur Hausen A, Brunton VG, Morton J, Sansom O, Schüler J, Stemmler MP, Herzberger C, Hopt U, Keck T, Brabletz S and Brabletz T: The EMT-activator ZEB1 promotes tumorigenicity by repressing stemness-inhibiting microRNAs. Nat Cell Biol 11: 1487-1495, 2009 .
23. Yu F, Yao H, Zhu P, Zhang X, Pan Q, Gong C, Huang Y, Hu X Su F, Lieberman J and Song E: let-7 regulates self renewal and tumorigenicity of breast cancer cells. Cell 131: 1109-1123, 2007.

24. Brabletz T, Jung A, Spaderna S, Hlubek F and Kirchner T: Opinion: migrating cancer stem cells - an integrated concept of malignant tumour progression. Nat Rev Cancer 5: 744-749, 2005.

25. Albino D, Longoni N, Curti L, Mello-Grand M, Pinton S, Civenni G, Thalmann G, D'Ambrosio G, Sarti M, Sessa F, Chiorino G, Catapano CV and Carbone GM: ESE3/EHF controls epithelial cell differentiation and its loss leads to prostate tumors with mesenchymal and stem-like features. Cancer Res 72: 2889-2900, 2012

26. Bao B, Wang Z, Ali S, Kong D, Banerjee S, Ahmad A, Li Y, Azmi AS, Miele L and Sarkar FH: Over-expression of FoxM1 leads to epithelial-mesenchymal transition and cancer stem cell phenotype in pancreatic cancer cells. J Cell Biochem 112: 2296-2306, 2011.

27. Jiang R, Li Y, Xu Y, Zhou Y, Pang Y, Shen L, Zhao Y, Zhang J, Zhou J, Wang X and Liu Q: EMT and CSC-like properties mediated by the IKK $\beta / \mathrm{I} \kappa \mathrm{B} \alpha / \mathrm{RelA}$ signal pathway via the transcriptional regulator, Snail, are involved in the arsenite-induced neoplastic transformation of human keratinocytes. Arch Toxicol 87: 991-1000, 2013.

28. Jo M, Eastman BM, Webb DL, Stoletov K, Klemke R and Gonias SL: Cell signaling by urokinase-type plasminogen activator receptor induces stem cell-like properties in breast cancer cells. Cancer Res 70: 8948-8958, 2010.

29. Bao B, Wang Z, Ali S, Kong D, Li Y, Ahmad A, Banerjee S, Azmi AS, Miele L and Sarkar FH: Notch-1 induces epithelialmesenchymal transition consistent with cancer stem cell phenotype in pancreatic cancer cells. Cancer Lett 307: 26-36, 2011.

30. Morel AP, Lièvre M, Thomas C, Hinkal G, Ansieau S and Puisieux A: Generation of breast cancer stem cells through epithelial-mesenchymal transition. PLoS One 3: e2888, 2008.

31. Mani SA, Guo W, Liao MJ, Eaton EN, Ayyanan A, Zhou Y, Brooks M, Reinhard F, Zhang CC, Shipitsin M, Campbell LL, Polyak K, Brisken C, Yang J and Weinberg RA: The epithelialmesenchymal transition generates cells with properties of stem cells. Cell 133: 704-715, 2008.

32. Lan L, Luo Y, Cui D, Shi BY, Deng W, Huo LL, Chen HL, Zhang GY and Deng LL: Epithelial-mesenchymal transition triggers cancer stem cell generation in human thyroid cancer cells. Int J Oncol 43: 113-120, 2013.

33. Biddle A, Liang X, Gammon L, Fazil B, Harper LJ, Emich H, Costea DE and Mackenzie IC: Cancer stem cells in squamous cell carcinoma switch between two distinct phenotypes that are preferentially migratory or proliferative. Cancer Res 71 : 5317-5326, 2011

34. Chen C, Wei Y, Hummel M, Hoffmann TK, Gross M, Kaufmann AM and Albers AE: Evidence for epithelialmesenchymal transition in cancer stem cells of head and neck squamous cell carcinoma. PLoS One 6: e16466, 2011.

35. Han M, Liu M, Wang Y, Chen X, Xu J, Sun Y, Zhao L, Qu H, Fan Y and Wu C: Antagonism of miR-21 reverses epithelialmesenchymal transition and cancer stem cell phenotype through AKT/ERK1/2 inactivation by targeting PTEN. PLoS One 7: e39520, 2012

36. Chiou GY, Cherng JY, Hsu HS, Wang ML, Tsai CM, Lu KH, Chien Y, Hung SC, Chen YW, Wong CI, Tseng LM, Huang PI, Yu CC, Hsu WH and Chiou SH: Cationic polyurethanes-short branch PEI-mediated delivery of Mir145 inhibited epithelialmesenchymal transdifferentiation and cancer stem-like properties and in lung adenocarcinoma. J Control Release 159: 240-250, 2012

37. Nalls D, Tang SN, Rodova M, Srivastava RK and Shankar S: Targeting epigenetic regulation of miR-34a for treatment of pancreatic cancer by inhibition of pancreatic cancer stem cells. PLoS One 6: e24099, 2011.

38 Bao B, Ali S, Kong D, Sarkar SH, Wang Z, Banerjee S, Aboukameel A, Padhye S, Philip PA and Sarkar FH: Anti-tumor activity of a novel compound-CDF is mediated by regulating miR-21, miR-200, and PTEN in pancreatic cancer. PLoS One 6: e17850, 2011.

39. Bao B, Ali S, Banerjee S, Wang Z, Logna F, Azmi AS, Kong D, Ahmad A, Li Y, Padhye S and Sarkar FH: Curcumin analogue CDF inhibits pancreatic tumor growth by switching on suppressor microRNAs and attenuating EZH2 expression. Cancer Res 72: 335-345, 2012 . 